\title{
Review Article \\ Treating Chronic Pain with SSRIs: What Do We Know?
}

\author{
Elias Patetsos ${ }^{1}$ and Emilia Horjales-Araujo ${ }^{2}$ \\ ${ }^{1}$ Copenhagen University, 2200 Copenhagen, Denmark \\ ${ }^{2}$ Department of Anesthesia, Center of Head and Orthopedics, Copenhagen University Hospital, 2200 Copenhagen, Denmark
}

Correspondence should be addressed to Emilia Horjales-Araujo; emiliahorjales@gmail.com

Received 7 March 2016; Revised 30 May 2016; Accepted 12 June 2016

Academic Editor: Eldon R. Tunks

Copyright (C) 2016 E. Patetsos and E. Horjales-Araujo. This is an open access article distributed under the Creative Commons Attribution License, which permits unrestricted use, distribution, and reproduction in any medium, provided the original work is properly cited.

\begin{abstract}
Serotonin is a monoamine neurotransmitter that plays a major role in both nociception and mood regulation. Alterations in the 5-hydroxytryptophan (5HT) system have been reported in chronic pain patients. In recent years, Selective Serotonin Reuptake Inhibitors (SSRIs) have been suggested as an alternative treatment for chronic pain due to the fact that they are better tolerated presenting less secondary effects than other antidepressants such as tricyclic antidepressants. Although several clinical trials have been published, the effectiveness of SSRI as treatment for pain conditions is inconclusive. This review aims to summarise what is known, regarding the effectiveness of SSRI as a treatment for chronic pain conditions in adults. A total of 36 studies involving a total of 1898 participants were included in this review. Of the 36 trials included in the review, 2 used zimelidine as treatment, 3 used escitalopram, 4 used fluvoxamine, 4 used sertraline, 6 used citalopram, 8 used paroxetine, 9 used fluoxetine, and one used both citalopram and paroxetine. Because the trials included in this review are quite heterogeneous, only qualitative analyses were performed. SSRI seems to have an effect on most of chronic pain conditions; however, further clinical trials with good methodology leading to low risk of bias are needed in order to conclude once and for all the effect of this drug class as treatment for chronic pain conditions.
\end{abstract}

\section{Introduction}

According to the International Association for the Study of Pain, pain is defined as an unpleasant sensory and emotional experience associated with actual or potential tissue damage or described in terms of such damage [1]. Although there is no general consensus, chronic pain is accepted as pain that has lasted longer than three to six months [1]. Persistent or chronic pain seems to be reciprocally associated with depression and anxiety disorders; thus while chronic pain can lead to long lasting emotional disturbances, low mood state such as depression and anxiety increases the perception of acute and chronic pain [2-5].

Serotonin (5-hydroxytryptophan (5-HT)) is a monoamine neurotransmitter that plays a major role in both nociception and mood regulation [6-8]. Serotonin has long been associated with both central and peripheral regulation of the nociceptive signal $[8,9]$ and alterations in the $5 \mathrm{HT}$ system have been reported in chronic pain patients (for review see [10]). In recent years, considerable research efforts have focused on the role played by 5 -HT and its respective receptors in processing and modulating noxious information [6-8]. The 5-HT system represents a powerful system that can both decrease and increase the magnitude of pain following noxious stimulation.

An important modulator of 5HT transmission is the serotonin transporter (5HTT), which is essential for determining the intensity and duration of the serotoninergic signal $[11,12]$. Polymorphism in the serotonin transporter gene has been associated with altered pain experience [13, 14]. Antidepressants affecting the monoaminergic system are now part of the therapeutic strategy for treatment of several chronic pain conditions (for review see [15]). Selective Serotonin Reuptake Inhibitor (SSRI) is a family of antidepressants that exerts its action by inhibiting the reuptake of serotonin into the presynaptic neuron after serotonin has been released, affecting the duration and intensity of the serotonin communication [11]. In recent years, SSRIs have been proposed as alternative treatment for chronic pain due to the fact that they are better tolerated and present less secondary effects 
than other antidepressants such as tricyclic antidepressants (TCAs) [15]. Although several clinical trials have been published, the effectiveness of SSRIs as treatment for pain conditions is inconclusive. This review aims to summarise what is known, so far, regarding the effectiveness of SSRIs as a treatment for chronic pain.

\section{Materials and Methods}

A detailed description of the methods is published in the PROSPERO database under registration number CRD42014013777. In summary, studies that appeared potentially relevant were identified by literature search in the PubMed and Cochrane databases by the terms presented in supplementary Table 1 in Supplementary Material available online at http://dx.doi.org/10.1155/2016/2020915. Following Cochrane suggestions, a second search of published studies was carried out 6 and 12 months after the initial search (June 2015 and January 2015, resp.). A flow diagram of the screening process based on PRISMA Statement is presented in Figure 1. Studies were included for revision if they were clinical trials analyzing the effectiveness of SSRIs as treatment for chronic pain conditions in adult patients (intervention group). Patients receiving any placebo (containing no active substance) or any active substance employed to ameliorate pain outcome as well as patients not receiving a treatment were used as control group. Studies were excluded from the review if they were not clinical trial articles published in English, if they did not include chronic pain patients, or if they did not have pain assessment (e.g., pain intensity or analgesic consumption) as outcome. No authors were contacted for further data, and no study protocols or original data were examined.

The results of the literature search were evaluated firstly by screening the study titles and, subsequently, by screening the abstracts of the possible eligible studies. After the abstract screening, full text screening of possible eligible studies was performed. Data was extracted into an excel datasheet in order to minimise subjectivity. Extracted data included study design (presence of placebo arm, blinding, randomisation, and cross-over), number of patients, chronic pain conditions experienced by the patients, SSRI used as treatment, duration of the trial, documented adverse effects and change in pain score outcomes (e.g., intensity, frequency, and analgesic consumption), and primary outcome (Tables 1(a) and 1(b)). All aspects of the literature review process (e.g., screening, data extraction, and quality assessment) were carried out by two independent investigators. Quality of the included studies and presence of bias were assessed based on five domains proposed by the Cochrane Collaboration tool for assessing risk of bias (random sequence generation, allocation concealment, blinding of participant and personnel and of outcome assessment, incomplete outcome data, and selective reporting).

\section{Results}

A total of 58 studies were considered, of which 36 met the inclusion criteria. Of the 22 excluded studies, 6 included nonadults patients, 8 studies included patients with acute or experimental pain (nonchronic pain patients), and 8 subjects did not measure pain outcome. A total of 36 studies involving a total of 1898 participants were included in this review. The distribution of the 1898 patients included in pain conditions were as follows: 259 patients with fibromyalgia, 166 with somatoform pain disorder, 280 with chronic low back pain, 467 with chronic tension type headache or migraine, 103 with chronic pelvic pain, 42 with prostatodynia, 195 with noncardiac chest pain, 204 with diabetic painful neuropathy, 48 with painful polyneuropathy, 31 with central poststroke pain, and 40 with chronic musculoskeletal pain, and 63 participants included in two studies were not classified into type of chronic pain condition. The total number of patients included in the studies varied from 14 to 122 (see Table 2). Of the 36 trials included in the review, 2 used zimelidine as treatment, 3 used escitalopram, 4 used fluvoxamine, 4 used sertraline, 6 used citalopram, 8 used paroxetine, 9 used fluoxetine, and one used both citalopram and paroxetine. Because the trials included in this review are quite heterogeneous, only qualitative analyses were performed.

3.1. Risk of Bias. While nine of the trials have one "unclear" risk of bias, 23 trials presented one or more domain at "high risk" or at least two domains with "unclear" risk; and only four trials were evaluated to have "low risk" in all domains (see Table 3). Only two of the four trials with "low risk" of bias reported a significant effect of SSRI as treatment for chronic pain and fourteen of the studies at "high risk" of bias reported a significant effect of SSRI.

3.2. Effect of SSRI as Treatment for Chronic Pain. As shown in Table 2, six studies presented contradictory or inconclusive data (e.g., a reduction of analgesic consumptions but not on pain intensity was observed; effect on pain symptoms was observed by the physician but not on self-reported pain intensities). Five studies found no effect of the SSRI on pain outcomes. Two of these studies were done in larger samples of patients $[16,17]$ and only one mentioned sample size and power calculations [17]. The other four studies were done in samples of less than 40 patients and did not mention any sample size calculation; it is thus possible that these studies might be underpowered. Finally, the other 26 studies found a significant effect of the SSRI on chronic pain outcomes. Interestingly, all five studies analyzing the effect of fluvoxamine described a significant effect of the SSRI on pain outcomes. Similarly, all three studies using escitalopram reported a significant positive outcome.

To date, fluoxetine is the most studied SSRI in relation to chronic pain treatment. Although there are no studies reporting an insignificant effect of this SSRI, two trials found contradictory results, reporting that fluoxetine either had similar effect as desipramine (TCA) on chronic tension type headache [18] or had an effect of the SSRI on overall headache but not on migraine [19].

3.3. Zimelidine. Zimelidine was the first SSRI antidepressant to be produced. Although the drug had very significant effects as antidepressant, within a year and a half of its introduction, 


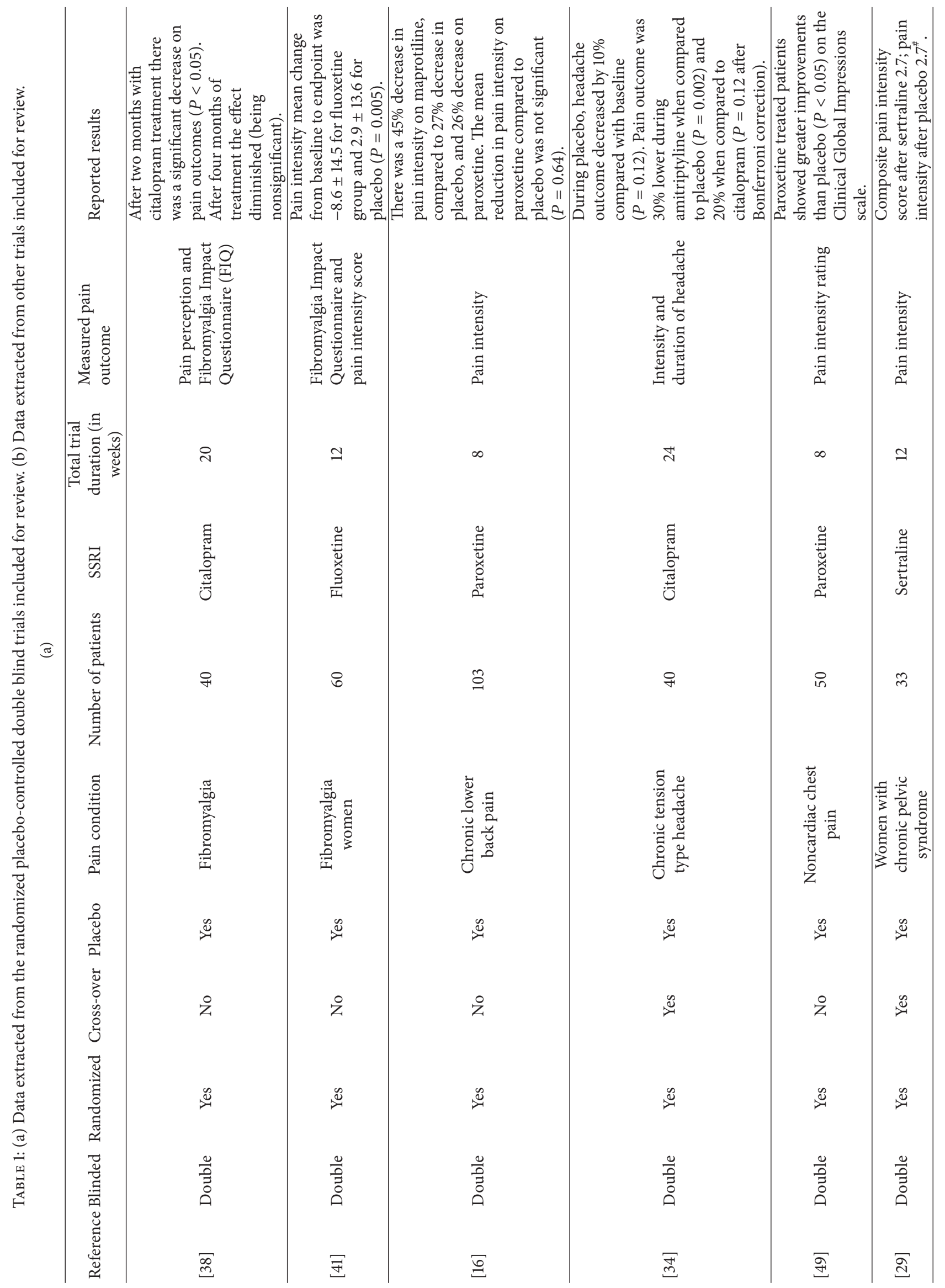




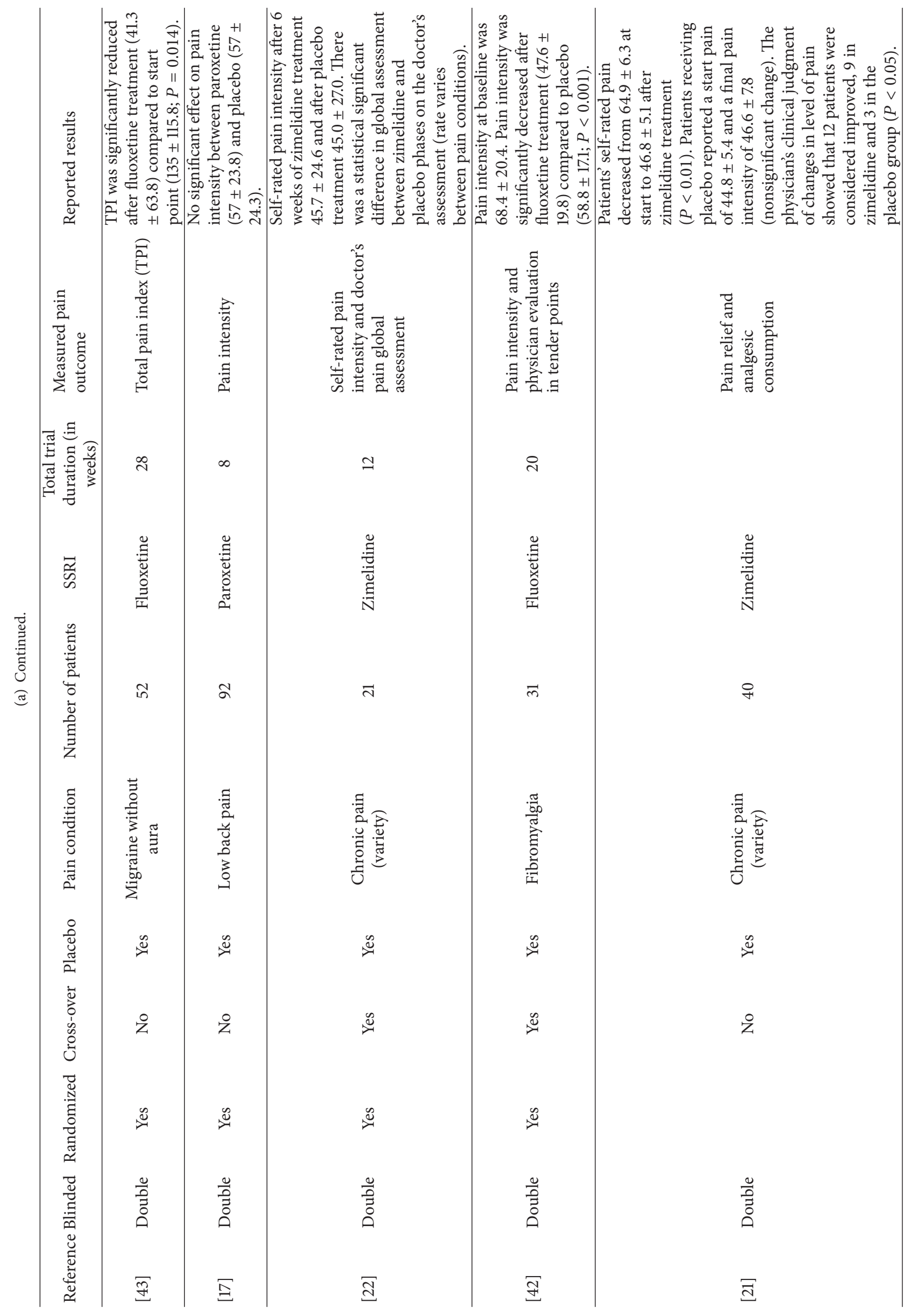




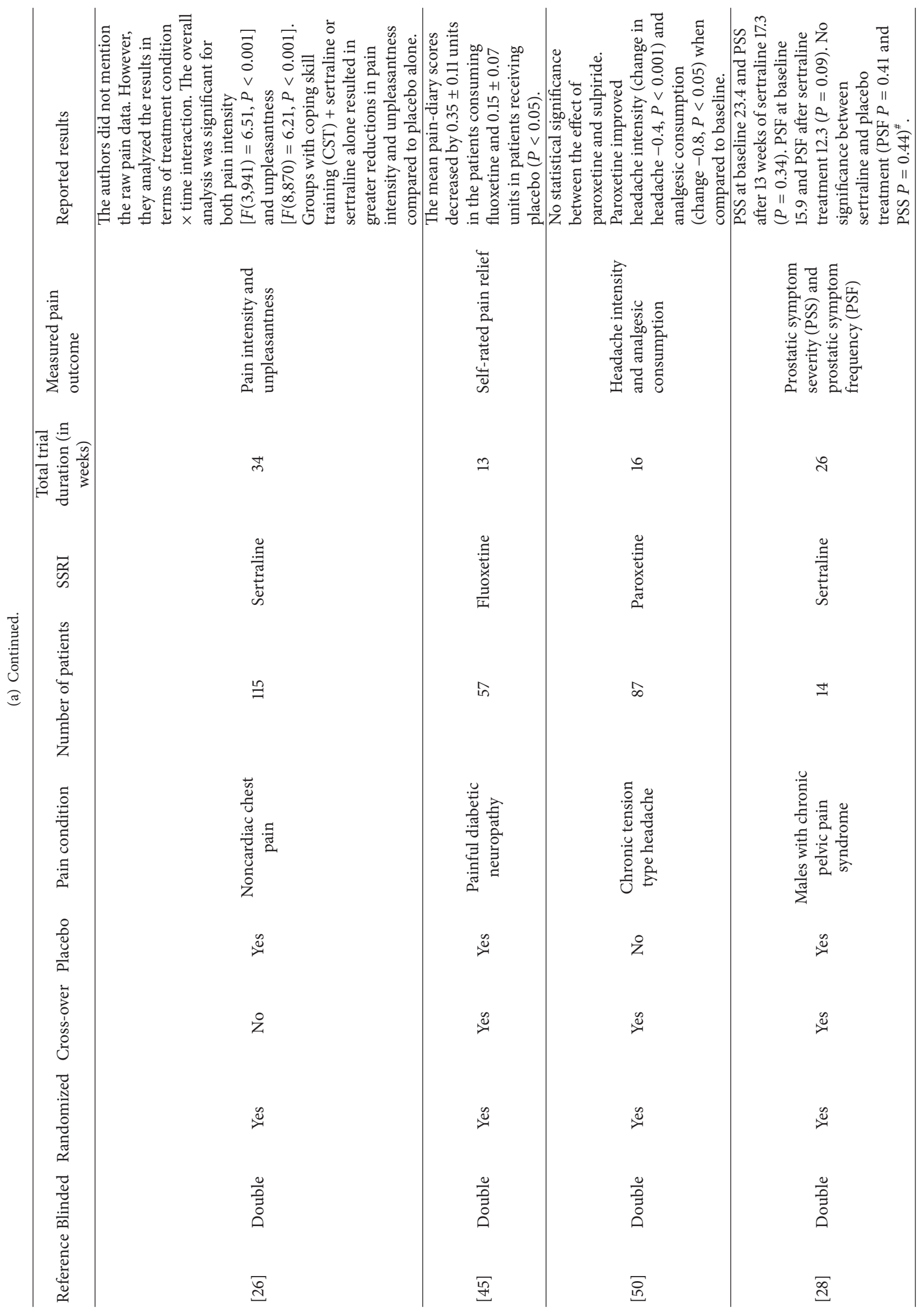




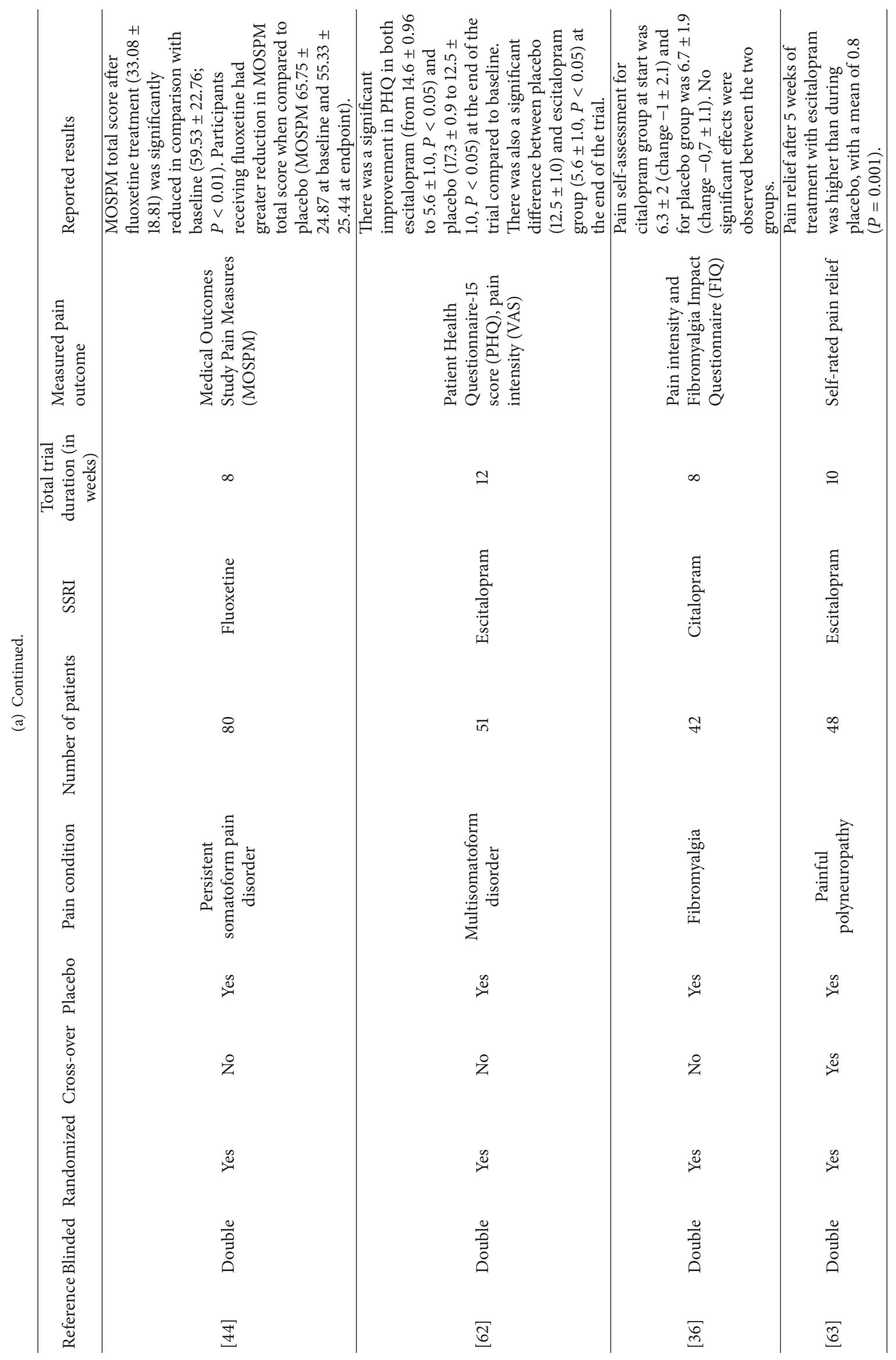




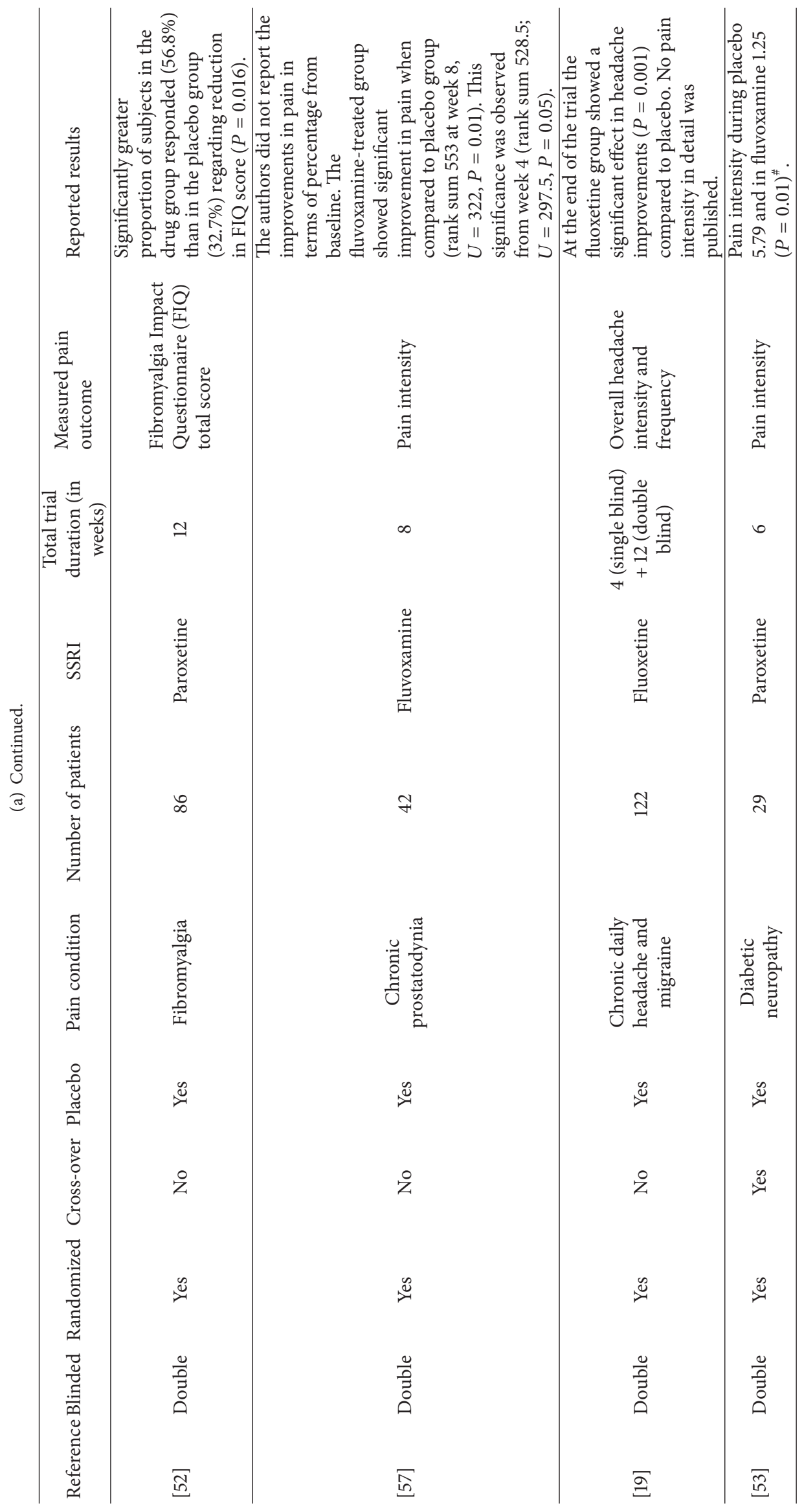




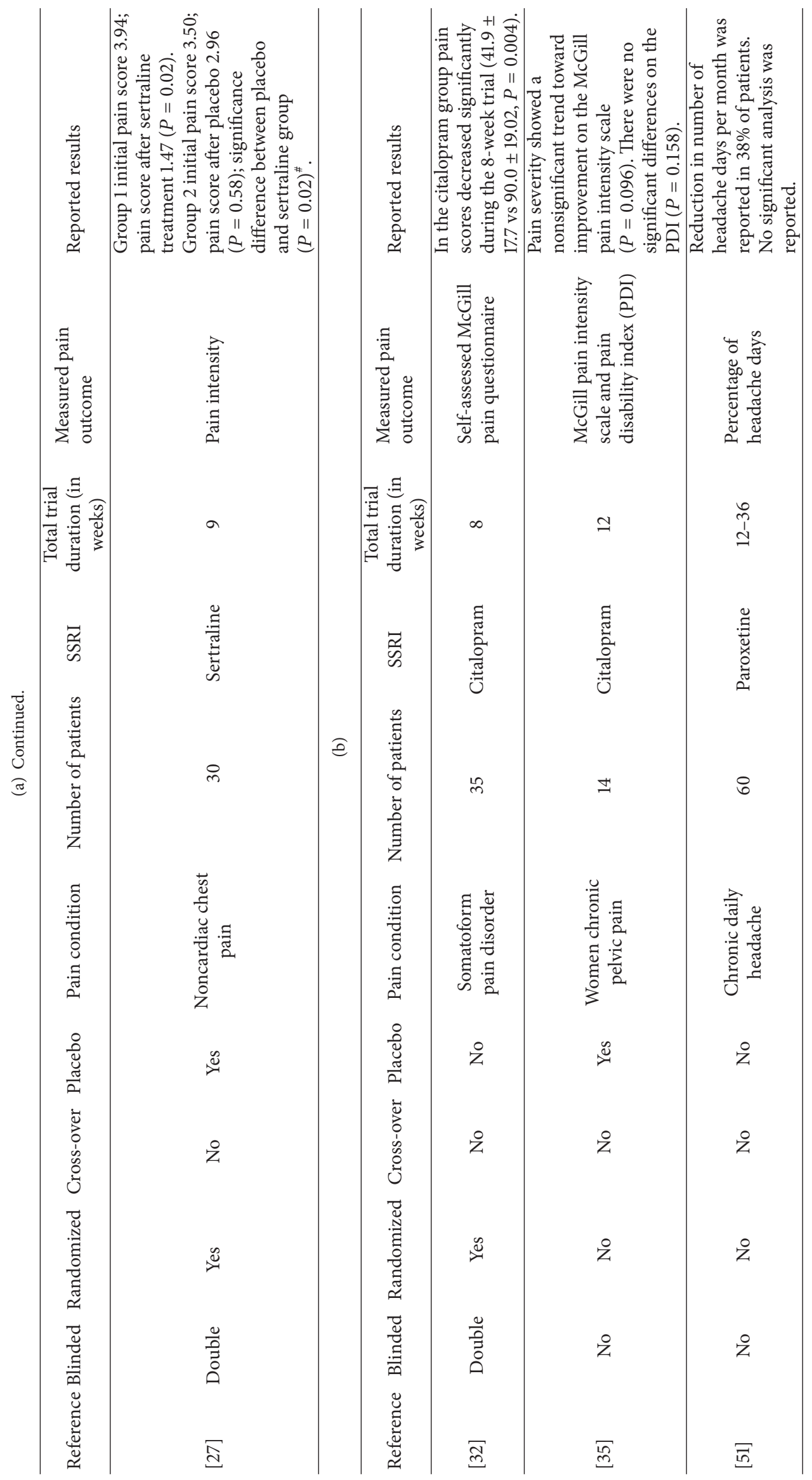




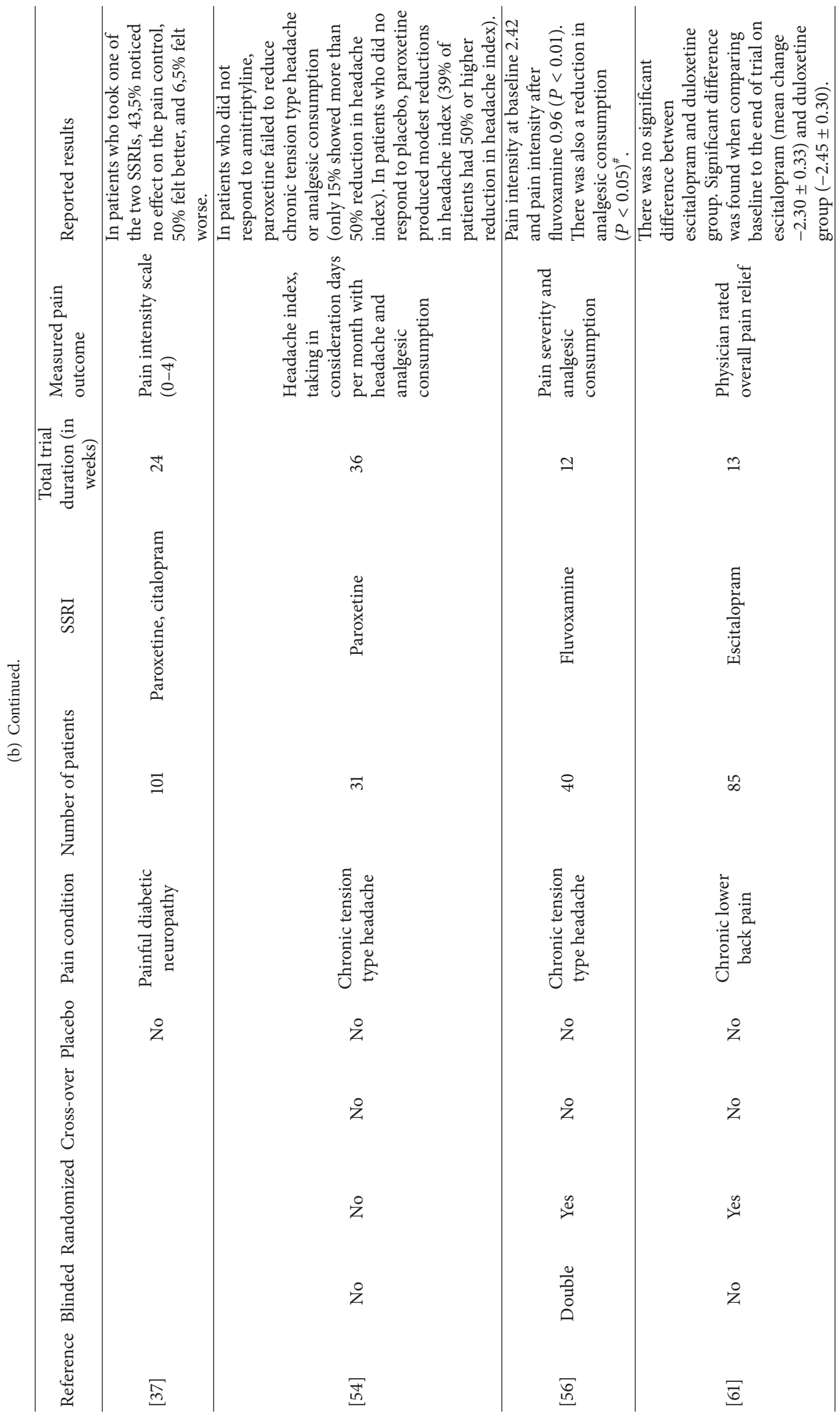




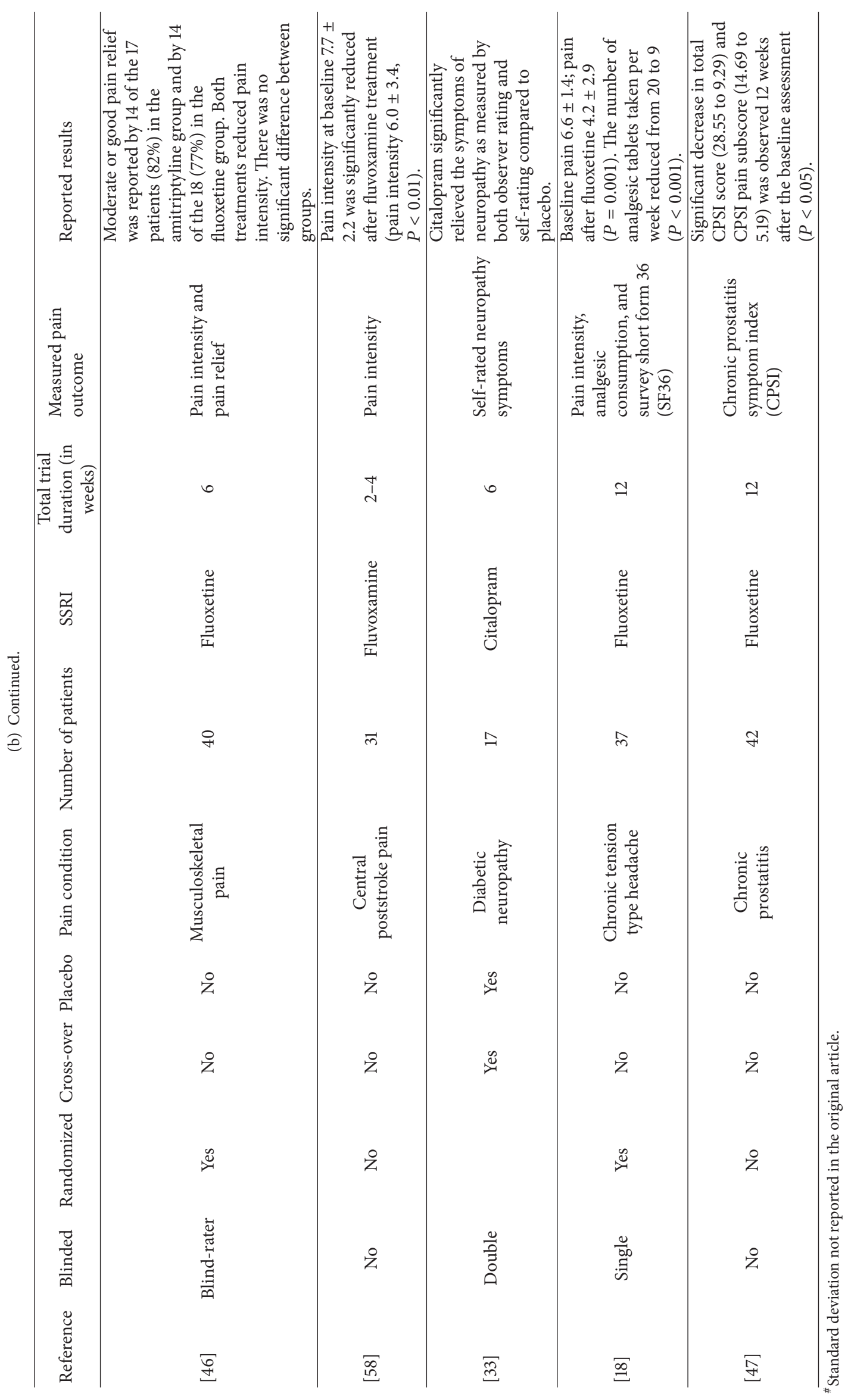


TABLE 2: Synopsis of the observed effect of the SSRI as treatment for chronic pain conditions.

\begin{tabular}{|c|c|c|c|}
\hline SSRI & Significant reduction in pain & No significant effect on pain & Inconclusive results \\
\hline Zimelidine & $\begin{array}{l}\text { Different chronic pain } \\
\text { syndromes [21] }\end{array}$ & & $\begin{array}{l}\text { Different chronic pain } \\
\text { syndromes [22] }\end{array}$ \\
\hline Sertraline & $\begin{array}{l}\text { Noncardiac chest pain }[26,27] \\
\text { Chronic pelvic pain }[28]\end{array}$ & Chronic pelvic pain [29] & \\
\hline Citalopram & $\begin{array}{l}\text { Somatoform pain disorder [32] } \\
\text { Diabetic neuropathy [33] }\end{array}$ & $\begin{array}{l}\text { Chronic tension type headache } \\
\text { [34] } \\
\text { Chronic pelvic pain [35] } \\
\text { Fibromyalgia [36] }\end{array}$ & $\begin{array}{l}\text { Painful diabetic neuropathy [37] } \\
\text { Fibromyalgia [38] }\end{array}$ \\
\hline Fluoxetine & $\begin{array}{l}\text { Fibromyalgia [41, 42] } \\
\text { Migraine without aura [43] } \\
\text { Persistent somatoform pain } \\
\text { disorder [44] } \\
\text { Painful diabetic neuropathy [45] } \\
\text { Musculoskeletal pain [46] } \\
\text { Chronic pelvic pain syndrome } \\
\text { [47] } \\
\text { Chronic daily headache [19] } \\
\text { Chronic tension type headache } \\
\text { [18] }\end{array}$ & & Migraine [19] \\
\hline Paroxetine & $\begin{array}{l}\text { Noncardiac chest pain [49] } \\
\text { Chronic headache [50] } \\
\text { Fibromyalgia [52] } \\
\text { Diabetic neuropathy [53] }\end{array}$ & $\begin{array}{l}\text { Chronic low back pain [16] } \\
\text { Chronic low back pain [17] }\end{array}$ & $\begin{array}{l}\text { Chronic tension type headache } \\
\text { [54] } \\
\text { Painful diabetic neuropathy [37] } \\
\text { Chronic headache [51] }\end{array}$ \\
\hline Fluvoxamine & $\begin{array}{l}\text { Chronic tension type headache } \\
\text { [56] } \\
\text { Prostatodynia [57] } \\
\text { Central poststroke pain [58] }\end{array}$ & & \\
\hline Escitalopram & $\begin{array}{l}\text { Chronic lower back pain [61] } \\
\text { Multisomatoform disorder [62] } \\
\text { Painful polyneuropathy [63] }\end{array}$ & & \\
\hline
\end{tabular}

some strong secondary effects (e.g., Guillain-Barré syndrome) were reported to be associated with the drug, forcing the withdrawal of the drug from the market [20]. There were, however, two studies that analysed the effect of zimelidine on chronic pain outcomes. Of those two studies, one observed a significant effect of the SSRI on pain relief (measured as pain intensity) and reduction in analgesic consumption compared with placebo [21]. However, the other study reported inconclusive results, while zimelidine significantly reduced pain outcome assessed by the physician; there were no significant differences in self-rated pain by the patients while consuming the drug compared to placebo, VAS $45.7 \pm 24.6$ and $45.0 \pm 27.0$, respectively [22].

3.4. Sertraline. Sertraline has mainly been used to treat depression and obsessive-compulsive disorders. Although sertraline is associated with a higher rate of side effects [2325], it has comparatively lower risk of drug interactions and can be combined with analgesics. Four trials analysed the possible effect of sertraline as chronic pain treatment. Two studies reported a significant effect of sertraline in noncardiac chest pain, measured in pain intensity and unpleasantness $[26,27]$. These two studies showed no significant change in mood between sertraline and a placebo group, suggesting that the effect of the SSRI on pain outcomes is not associated with an improvement in mood. On the offside, the rate of side effect reported in these two trials was quite high. A third study found an effect of sertraline on pain outcomes in males with chronic pelvic pain syndrome compared to baseline, but the difference was not significant when the intervention group was compared to placebo [28]. Finally, a fourth study reported that although sertraline slightly significantly improved the emotional state of the patients, the treatment had no statistically significant effect on the pain outcomes (pelvic pain intensity) [29].

3.5. Citalopram. Citalopram has been described to have antidepressant properties similar to tricyclic drugs but with significantly less side effects [30]. In animal models citalopram has been associated with analgesic effects [31]. However, in humans controversial data has been observed. Seven studies analysed the effect of citalopram on chronic pain outcomes. Two of the seven studies found a significant effect of the SSRI as treatment for chronic pain: somatoform pain disorder [32] and diabetic neuropathy [33], measured as pain intensity (VAS), total pain rating index, and observed and self-rated pain intensity and symptoms, respectively. Three studies found no effect in patients with chronic tension type headache [34], chronic pelvic pain [35], and fibromyalgia [36], measured as area under the headache curve, pain 
TABLE 3: Assessment of the risk of bias of the included studies.

\begin{tabular}{|c|c|c|c|c|c|c|}
\hline Reference & $\begin{array}{c}\text { Random } \\
\text { sequence } \\
\text { generation }\end{array}$ & $\begin{array}{c}\text { Allocation } \\
\text { concealment }\end{array}$ & $\begin{array}{c}\text { Blinding of } \\
\text { participants and } \\
\text { personnel }\end{array}$ & $\begin{array}{l}\text { Blinding of } \\
\text { primary outcome } \\
\text { assessment }\end{array}$ & $\begin{array}{l}\text { Incomplete } \\
\text { outcome data }\end{array}$ & Selective reporting \\
\hline$[38]$ & - & $?$ & - & - & - & - \\
\hline [32] & - & $?$ & - & - & - & - \\
\hline [41] & $?$ & - & - & - & + & - \\
\hline [16] & - & - & - & - & - & - \\
\hline [34] & $?$ & - & - & - & - & - \\
\hline [35] & $?$ & + & + & + & - & - \\
\hline [43] & $?$ & - & - & - & - & - \\
\hline [17] & - & - & - & - & - & - \\
\hline [49] & $?$ & - & - & - & - & - \\
\hline [29] & $?$ & $?$ & - & - & + & - \\
\hline [51] & + & + & + & + & $?$ & - \\
\hline [22] & $?$ & $?$ & - & - & - & - \\
\hline [37] & + & $?$ & + & + & - & - \\
\hline [42] & - & - & - & - & + & - \\
\hline [54] & + & + & + & + & - & - \\
\hline [21] & $?$ & $?$ & - & - & $?$ & - \\
\hline$[26]$ & - & + & + & $?$ & - & - \\
\hline$[50]$ & $?$ & - & - & $?$ & $?$ & - \\
\hline [28] & $?$ & $?$ & + & + & $?$ & - \\
\hline$[44]$ & $?$ & $?$ & - & - & $?$ & - \\
\hline [56] & + & - & - & - & $?$ & - \\
\hline$[45]$ & $?$ & - & - & - & $?$ & - \\
\hline [61] & $?$ & $?$ & + & + & - & - \\
\hline [62] & - & - & - & - & - & - \\
\hline [36] & $?$ & - & - & - & $?$ & - \\
\hline [63] & - & - & - & - & - & - \\
\hline [52] & - & - & + & + & - & - \\
\hline [19] & - & - & - & - & - & - \\
\hline [46] & $?$ & $?$ & + & - & $?$ & - \\
\hline [58] & + & + & + & + & - & - \\
\hline [53] & $?$ & - & - & - & $?$ & - \\
\hline [33] & $?$ & - & - & - & + & - \\
\hline [57] & - & - & - & - & $?$ & - \\
\hline [27] & - & - & - & - & $?$ & - \\
\hline [18] & $?$ & - & - & - & - & - \\
\hline [47] & + & + & + & + & - & - \\
\hline
\end{tabular}

-: low risk, + : high risk, and ?: unknown risk.

disability index, and McGill pain questionnaire and pain tender points and fibromyalgia symptoms, respectively. In addition, two studies reported inconclusive results on selfrated pain in patients suffering from painful diabetic neuropathy [37] and fibromyalgia [38].

3.6. Fluoxetine. Fluoxetine was the third most prescribed antidepressant after sertraline and citalopram in 2010 [39]. Its effect on serotonin system and receptors is well known but its effect on other receptors is not well understood. In an openlabelled, placebo-controlled trial, Gordon and colleagues found that fluoxetine given 7 days before molar surgery inhibited the analgesic effect of morphine; therefore the authors suggested an SSRI action on the mu $(\mu)$ receptors [40].

Ten studies included in this review used fluoxetine as treatment for different chronic pain conditions. Nine trials reported a positive effect of the SSRI on chronic pain outcomes: fibromyalgia [41,42] (measured by pain scores and 


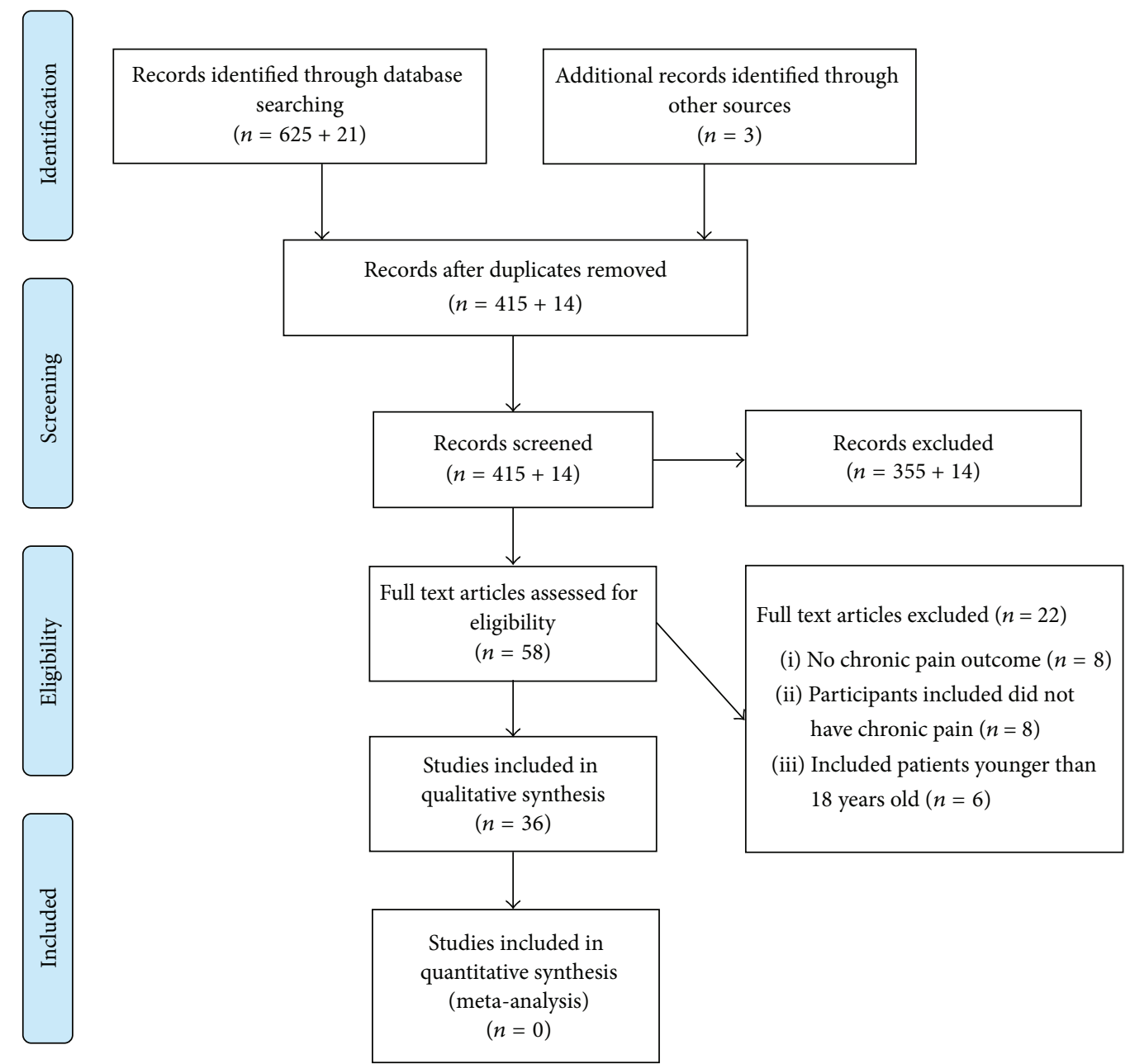

FIGURE 1: Diagram of the publications screening process based on PRISMA Statement (original search + search 6 months after).

Fibromyalgia Impact Questionnaire scores), chronic tension type headache [18] patients (measured as self-reported improvement), migraine without aura [43] (total pain index), persistent somatoform pain disorder [44] (medical outcomes study pain scores), painful diabetic neuropathy [45] (measured as self-rated pain), musculoskeletal pain [46] (measured as pain intensity and relief), chronic pelvic pain syndrome [47] (chronic prostatitis index), and chronic daily headache [19] (measured as VAS pain intensity). An additional study reported inconclusive results on migraine [19] (measured as VAS pain intensity).

3.7. Paroxetine. When released, paroxetine was the most potent and selective of all SSRI available [48]. A total of nine studies examined the use of paroxetine as treatment for chronic pain. Four studies found an amelioration of pain outcomes: self-rated pain intensity by noncardiac chest pain patients [49], chronic headache [50, 51], fibromyalgia [52] measured by Fibromyalgia Impact Questionnaire, and pain intensity experienced by diabetic neuropathy patients [53]. On the other hand, two studies found no effect of the SSRI on pain intensity in chronic low back patients $[16,17]$ and three trials described inconclusive results in chronic tension type headache [54] (measured by days where the patients experienced headache), chronic headache [50, 51], and selfreported pain improvement by painful diabetic neuropathy patients [37].

3.8. Fluvoxamine. Fluvoxamine is a potent and selective SSRI with approximately 100 -fold affinity for the serotonin transporter over the norepinephrine transporter [55]. Three publications were found to analyse the effect of fluvoxamine on chronic pain outcomes. All three studies found a positive effect of the drug on chronic tension type headache [56] (assessed by frequency of headaches and pain severity), selfrated pain duration and intensity by prostatodynia patients [57], and central poststroke pain [58] measured by pain intensity.

3.9. Escitalopram. Escitalopram is the (S)-stereoisomer (enantiomer) of citalopram, hence the name. Some studies suggest that escitalopram might be more effective than citalopram in treating depressed patients $[59,60]$. All three studies analysing the effect of escitalopram as treatment for 
chronic pain reported positive results: chronic lower back pain [61] measured as weekly pain relief, multisomatoform disorder (pain intensity) [62] and painful polyneuropathy [63] (evaluated by self-rated pain relief).

\section{Discussion}

Serotonin (5HT) is a monoamine neurotransmitter that plays a major role in both nociception and mood regulation [6-8]. A major player in 5-HT signalling is the serotonin transporter (5-HTT), which is essential for determining the 5-HT level at the postsynaptic receptor (for review see [11]). SSRIs act upon the 5-HTT inhibiting the reuptake of the monoamine into the presynaptic cell, increasing the level of serotonin in the synaptic cleft. In the past decades, SSRIs have emerged as alternative treatment for chronic pain but their effectiveness is inconclusive.

This topical review aimed to summarise what is known about the effectiveness of the use of SSRI as treatment for chronic pain. A total of 36 trials were included in this revision. Twenty-five studies reported a significant effect of SSRI on chronic pain outcomes. However, only two of these studied were categorised as having "low risk" of bias.

In general, most studies do not seem to be congruent on the methodology adopted and present a "high risk" of bias: lacking a control-group (placebo or other drugs), not including sample size calculation, lacking randomisation (or not describing method of randomisation), or even lacking blinding of the researcher and/or patients. To date, fluoxetine is the most studied SSRI in relation with chronic pain treatment. No studies reported an insignificant effect of this SSRI; however one study found contradictory results reporting an effect on overall headache but not on migraine [19].

More than $70 \%$ of the studies included in this review found a statistically significant effect of SSRI as treatment for chronic pain conditions. Fluoxetine, fluvoxamine, and escitalopram in particular seem to be the most promising SSRI. Further studies using those SSRIs in different concentrations and with a systematic methodology minimising bias (proper blinding, randomisation of patients, placebo (or active comparator) control, and perhaps a cross-over period) are of high importance in order to assure the use of optimal dosage and treatment periods in the clinical practice. Furthermore, the studies reviewed here were of short duration, varying from 2 to 36 weeks. Since chronic pain conditions often evolve into permanent pain (lasting for even a lifetime), future studies with longer treatment period are strongly encouraged.

Chronic pain and depression are highly prevalent conditions whose symptoms overlap. A large number of studies have found a reciprocal association between emotions (especially depression) and pain [64-69]. Since SSRIs are designed and used to treat depression and other psychological disorders, it would be of great interest to investigate if the effectiveness of SSRIs as treatment for chronic pain is mediated by its effect as mood regulator. Future studies focusing on how does SSRI effectiveness as pain treatment compare to that of TCAs and to the newer SNRIs are also needed. Perhaps SSRIs differ from TCAs as treatment for chronic pain conditions by having different effect on mood modulation. If SSRIs act on pain conditions by modulating the emotional state, longer treatment periods might be required in order to observe a positive effect. If this is the case, studies with short SSRI treatment duration (as many of the trials included in this review) would not be able to show a significant effect on the pain conditions. This strengthens the necessity of longer trials studying the effect of SSRI on mood states and chronic pain conditions.

Statistical significant effect of SSRI on chronic pain was not always observed; however the clinical significance of the relation between SSRI and chronic pain cannot be ruled out. The clinical significance of the SSRI effectiveness as treatment for chronic pain was not always analysed in the trials included in this revision. A statistical significance numerical difference in pain intensity will not always imply a clinical significance (patient's life quality). For example, one of the studies found a significant effect when pain outcome was measured by the physician but no statistical significance was seen when selfrated pain by the patient was analysed [22]. In this aspect it is also important to remark the trial analysing the effect of sertraline on pelvic pain intensity; while an improved emotional state was observed on the patients, the treatment had no statistically significant effect on the pain outcomes [29]. Thus, although the patients' life quality improved by improving their mood, the pain intensity reminded unchanged. This opens to the discussion of whether a statistically significant physiological effect of SSRI on pain outcomes is enough to generate a clinical significant effect (e.g., emotional state) or not, and vice versa.

Generally chronic pain patients have tried several treatments, feeling desolated and without hope of being pain-free. The fact that SSRIs have a meaningful improvement in pain symptoms for many patients involved in the trials, in addition to the SSRI's safety profile with low frequencies of adverse events, might open for the discussion of choosing SSRI over other drugs, for example, TCA or gabapentin, to treat chronic pain conditions in the clinical practice. Clinicians are recommended to analyse in a case by case basis whether the use of SSRI to treat chronic pain conditions might improve the patient's life quality, for example, in patients who have tried other treatments without success or patients who have been successfully treated with TCAs but had to discontinue the treatment due to the experienced adverse events. Patients with mild chronic pain conditions might also be beneficiated of having SSRI as first treatment due to the safety profile, before trying a more aggressive treatment as, for example, TCAs.

The present review has some limitations: first, the methodology adopted might have excluded data since only published articles in English were included; furthermore and in contradiction with PRISMA recommendations, unpublished clinical trials were not included in the present review; therefore potential studies may not have been included in this revision. Secondly, the authors were not contacted for additional data and clarification; perhaps by contacting the authors, more information could be gathered regarding the methodology used in each study, facilitating further analysis and conclusion. In addition, studies analysed in this review comprehended seven different SSRIs and a variety of chronic pain conditions and pain outcome measurements increasing 
the heterogeneity of the studied population. Finally, metaanalysis was not done, and only qualitative data is presented in this review.

A meta-analysis would be of great help in order to quantitatively measure the effect of SSRI on chronic pain conditions. However, precautions should be taken when performing the recommended meta-analysis. The high heterogeneity in the existing clinical trials in regard to the pain conditions, the pain outcome measurements, and the demographic of the patients studied, in addition to the poor risk of bias contingency, might lead to a poor statistical analysis. It is thus a priority to improve the quality and consistency of future clinical trials studying the effect of SSRI on chronic pain conditions including a control group (e.g., placebo, TCA, or gabapentin).

\section{Conclusion}

SSRI seems to have an effect on most of chronic pain conditions; however further clinical trials with a good methodology leading to low risk of bias are needed in order to conclude once and for all the effect of this drug as treatment for chronic pain conditions. In addition, it will be of great interest to continue this review with a meta-analysis study following PRISMA and Cochrane Collaboration guidelines in order to statistically asses the published data.

\section{Additional Points}

This review aims to summarise what is known, regarding the effectiveness of SSRI, as a treatment for chronic pain conditions in adults. A total of 36 studies were included in this review. Because the trials included in this review are quite heterogeneous, only qualitative analyses were performed. SSRI seems to have an effect on most of chronic pain conditions; however further clinical trials with good methodology leading to low risk of bias are needed in order to conclude once and for all the effect of this drug class as treatment for chronic pain conditions.

\section{Competing Interests}

Although Emilia Horjales-Araujo currently works at Ferring Pharmaceuticals, all work done in relation to this study was performed during Emilia Horjales-Araujo postdoc at Copenhagen University Hospital, 2 years before starting at Ferring Pharmaceuticals. Furthermore, Ferring do not have any SSRI in its portfolio. Thus, there is no conflict of interests.

\section{Acknowledgments}

The authors would like to thank Joergen B. Dahl for his helpful discussions and comments on the paper. Spiros Lukas for his help with the language revision of the paper.

\section{References}

[1] H. Merskey and M. Bogduk, Classification of Chronic Pain: Descriptions of Chronic Pain Syndromes and Definitions of Pain Terms, IASP Press, Seattle, Wash, USA, 1994.
[2] D. D. Price, "Psychological and neural mechanisms of the affective dimension of pain," Science, vol. 288, no. 5472, pp. 1769-1772, 2000.

[3] S. M. Stahl, "Fibromyalgia-pathways and neurotransmitters," Human Psychopharmacology, vol. 24, supplement 1, pp. S11-S17, 2009.

[4] G. Magni, C. Moreschi, S. Rigatti-Luchini, and H. Merskey, "Prospective study on the relationship between depressive symptoms and chronic musculoskeletal pain," Pain, vol. 56, no. 3, pp. 289-297, 1994.

[5] L. J. Carroll, J. D. Cassidy, and P. Côté, "Depression as a risk factor for onset of an episode of troublesome neck and low back pain," Pain, vol. 107, no. 1-2, pp. 134-139, 2004.

[6] N. E. Rosenthal, C. M. Mazzanti, R. L. Barnett et al., "Role of serotonin transporter promoter repeat length polymorphism (5-HTTLPR) in seasonality and seasonal affective disorder," Molecular Psychiatry, vol. 3, no. 2, pp. 175-177, 1998.

[7] C. A. Lowry, S. L. Lightman, and D. J. Nutt, “That warm fuzzy feeling: brain serotonergic neurons and the regulation of emotion," Journal of Psychopharmacology, vol. 23, no. 4, pp. 392-400, 2009.

[8] M. J. Millan, "Serotonin (5-HT) and pain: a reappraisal of its role in the light of receptor multiplicity," Seminars in Neuroscience, vol. 7, no. 6, pp. 409-419, 1995.

[9] M. J. Millan, "Serotonin and pain: evidence that activation of 5HT1A receptors does not elicit antinociception against noxious thermal, mechanical and chemical stimuli in mice," Pain, vol. 58, no. 1, pp. 45-61, 1994.

[10] M. J. Millan, “Descending control of pain," Progress in Neurobiology, vol. 66, no. 6, pp. 355-474, 2002.

[11] A. R. Hariri and A. Holmes, "Genetics of emotional regulation: the role of the serotonin transporter in neural function," Trends in Cognitive Sciences, vol. 10, no. 4, pp. 182-191, 2006.

[12] K.-P. Lesch, U. Balling, J. Gross et al., "Organization of the human serotonin transporter gene," Journal of Neural Transmission, vol. 95, no. 2, pp. 157-162, 1994.

[13] E. Horjales-Araujo, D. Demontis, E. K. Lund et al., "Emotional modulation of muscle pain is associated with polymorphisms in the serotonin transporter gene," Pain, vol. 154, no. 8, pp. 14691476, 2013.

[14] F. Lindstedt, J. Berrebi, E. Greayer et al., "Conditioned pain modulation is associated with common Polymorphisms in the serotonin transporter gene," PLoS ONE, vol. 6, no. 3, Article ID e18252, 2011.

[15] P. Dharmshaktu, V. Tayal, and B. S. Kalra, "Efficacy of antidepressants as analgesics: a review," Journal of Clinical Pharmacology, vol. 52, no. 1, pp. 6-17, 2012.

[16] J. H. Atkinson, M. A. Slater, D. R. Wahlgren et al., "Effects of noradrenergic and serotonergic antidepressants on chronic low back pain intensity," Pain, vol. 83, no. 2, pp. 137-145, 1999.

[17] C. Dickens, M. Jayson, C. Sutton, and F. Creed, "The relationship between pain and depression in a trial using paroxetine in sufferers of chronic low back pain," Psychosomatics, vol. 41, no. 6, pp. 490-499, 2000.

[18] Z. Walker, R. W. H. Walker, M. M. Robertson, and S. Stansfeld, "Antidepressant treatment of chronic tension-type headache: a comparison between fluoxetine and desipramine," Headache, vol. 38, no. 7, pp. 523-528, 1998.

[19] J. R. Saper, S. D. Silberstein, A. E. Lake III, and M. E. Winters, "Double-blind trial of fluoxetine: chronic daily headache and migraine," Headache, vol. 34, no. 9, pp. 497-502, 1994. 
[20] J. Fagius, P. O. Osterman, A. Siden, and B.-E. Wiholm, "Guullain-Barre syndrome following zimeldine treatment," Journal of Neurology Neurosurgery and Psychiatry, vol. 48, no. 1, pp. 65-69, 1985.

[21] F. Johansson and L. Von Knorring, "A double-blind controlled study of a serotonin uptake inhibitor (Zimelidine) versus placebo in chronic pain patients," Pain, vol. 7, no. 1, pp. 69-78, 1979.

[22] G. K. Gourlay, D. A. Cherry, M. J. Cousins, B. L. Love, J. R. Graham, and M. O. McLachlan, "A controlled study of a serotonin reuptake blocker, zimelidine, in the treatment of chronic pain," Pain, vol. 25, no. 1, pp. 35-52, 1986.

[23] G. Maina, U. Albert, V. Salvi, and F. Bogetto, "Weight gain during long-term treatment of obsessive-compulsive disorder: a prospective comparison between serotonin reuptake inhibitors," Journal of Clinical Psychiatry, vol. 65, no. 10, pp. 1365-1371, 2004.

[24] M. Fava, R. Judge, S. L. Hoog, M. E. Nilsson, and S. C. Koke, "Fluoxetine versus sertraline and paroxetine in major depressive disorder: changes in weight with long-term treatment," Journal of Clinical Psychiatry, vol. 61, no. 11, pp. 863-867, 2000.

[25] M. Siepmann, J. Grossmann, M. Mück-Weymann, and W. Kirch, "Effects of sertraline on autonomic and cognitive functions in healthy volunteers," Psychopharmacology, vol. 168, no. 3, pp. 293-298, 2003.

[26] F. J. Keefe, R. A. Shelby, T. J. Somers et al., "Effects of coping skills training and sertraline in patients with non-cardiac chest pain: a randomized controlled study," Pain, vol. 152, no. 4, pp. 730-741, 2011.

[27] I. Varia, E. Logue, C. O'Connor et al., "Randomized trial of sertraline in patients with unexplained chest pain of noncardiac origin," American Heart Journal, vol. 140, no. 3, pp. 367-372, 2000.

[28] R. A. Lee, R. M. West, and J. D. Wilson, "The response to sertraline in men with chronic pelvic pain syndrome," Sexually Transmitted Infections, vol. 81, no. 2, pp. 147-149, 2005.

[29] C. C. Engel Jr., E. A. Walker, A. L. Engel, J. Bullis, and A. Armstrong, "A randomized, double-blind crossover trial of sertraline in women with chronic pelvic pain," Journal of Psychosomatic Research, vol. 44, no. 2, pp. 203-207, 1998.

[30] P. Bech and P. Cialdella, "Citalopram in depression-metaanalysis of intended and unintended effects," International Clinical Psychopharmacology, vol. 6, supplement 5, pp. 45-54, 1992.

[31] D. Ardid, H. Marty, J. Fialip, A. M. Privat, A. Eschalier, and J. Lavarenne, "Comparative effects of different uptake inhibitor antidepressants in two pain tests in mice," Fundamental and Clinical Pharmacology, vol. 6, no. 2, pp. 75-82, 1992.

[32] M. Aragona, L. Bancheri, D. Perinelli et al., "Randomized double-blind comparison of serotonergic (Citalopram) versus noradrenergic (Reboxetine) reuptake inhibitors in outpatients with somatoform, DSM-IV-TR pain disorder," European Journal of Pain, vol. 9, no. 1, pp. 33-38, 2005.

[33] S. H. Sindrup, U. Bjerre, A. Dejgaard, K. Brøsen, T. AaesJørgensen, and L. F. Gram, "The selective serotonin reuptake inhibitor citalopram relieves the symptoms of diabetic neuropathy," Clinical Pharmacology and Therapeutics, vol. 52, no. 5, pp. 547-552, 1992.

[34] L. Bendtsen, R. Jensen, and J. Olesen, "A non-selective (amitriptyline), but not a selective (citalopram), serotonin reuptake inhibitor is effective in the prophylactic treatment of chronic tension-type headache," Journal of Neurology Neurosurgery and Psychiatry, vol. 61, no. 3, pp. 285-290, 1996.
[35] C. S. Brown, A. S. Franks, J. Wan, and F. W. Ling, "Citalopram in the treatment of women with chronic pelvic pain: an openlabel trial," The Journal of Reproductive Medicine, vol. 53, no. 3, pp. 191-195, 2008.

[36] J. Nørregaard, H. Volkmann, and B. Danneskiold-Samstøe, "A randomized controlled trial of citalopram in the treatment of fibromyalgia," Pain, vol. 61, no. 3, pp. 445-449, 1995.

[37] S. Giannopoulos, M. Kosmidou, I. Sarmas et al., "Patient compliance with SSRIs and gabapentin in painful diabetic neuropathy," Clinical Journal of Pain, vol. 23, no. 3, pp. 267-269, 2007.

[38] U. M. Anderberg, I. Marteinsdottir, and L. von Knorring, "Citalopram in patients with fibromyalgia-a randomized, double-blind, placebo-controlled study," European Journal of Pain, vol. 4, no. 1, pp. 27-35, 2000.

[39] Verispan, Top 200 Generic Drugs by Units in 2010, Drug Topics, 2010.

[40] N. C. Gordon, P. H. Heller, R. W. Gear, and J. D. Levine, "Interactions between fluoxetine and opiate analgesia for postoperative dental pain," Pain, vol. 58, no. 1, pp. 85-88, 1994.

[41] L. M. Arnold, E. V. Hess, J. I. Hudson, J. A. Welge, S. E. Berno, and P. E. Keck Jr., "A randomized, placebo-controlled, doubleblind, flexible-dose study of fluoxetine in the treatment of women with fibromyalgia," The American Journal of Medicine, vol. 112, no. 3, pp. 191-197, 2002.

[42] D. Goldenberg, M. Mayskiy, C. Mossey, R. Ruthazer, and C. Schmid, "A randomized, double-blind crossover trial of fluoxetine and amitriptyline in the treatment of fibromyalgia," Arthritis \& Rheumatism, vol. 39, no. 11, pp. 1852-1859, 1996.

[43] C. Colucci D’Amato, V. Pizza, T. Marmolo, E. Giordano, V. Alfano, and A. Nasta, "Fluoxetine for migraine prophylaxis: a double-blind trial," Headache, vol. 39, no. 10, pp. 716-719, 1999.

[44] Y.-L. Luo, M.-Y. Zhang, W.-Y. Wu, C.-B. Li, Z. Lu, and Q.-W. Li, "A randomized double-blind clinical trial on analgesic efficacy of fluoxetine for persistent somatoform pain disorder," Progress in Neuro-Psychopharmacology and Biological Psychiatry, vol. 33, no. 8, pp. 1522-1525, 2009.

[45] M. B. Max, S. A. Lynch, J. Muir, S. E. Shoaf, B. Smoller, and R. Dubner, "Effects of desipramine, amitriptyline, and fluoxetine on pain in diabetic neuropathy," The New England Journal of Medicine, vol. 326, no. 19, pp. 1250-1256, 1992.

[46] S. Schreiber, S. Vinokur, V. Shavelzon, C. G. Pick, E. Zahavi, and Y. Shir, "A randomized trial of fluoxetine versus amitriptyline in musculo-skeletal pain," Israel Journal of Psychiatry and Related Sciences, vol. 38, no. 2, pp. 88-94, 2001.

[47] D. Xia, P. Wang, J. Chen, S. Wang, and H. Jiang, "Fluoxetine ameliorates symptoms of refractory chronic prostatitis/chronic pelvic pain syndrome," Chinese Medical Journal, vol. 124, no. 14, pp. 2158-2161, 2011.

[48] I. F. Tulloch and A. M. Johnson, "The pharmacologic profile of paroxetine, a new selective serotonin reuptake inhibitor," Journal of Clinical Psychiatry, vol. 53, no. 2, pp. 7-12, 1992.

[49] P. M. Doraiswamy, I. Varia, C. Hellegers et al., "A randomized controlled trial of paroxetine for noncardiac chest pain," Psychopharmacology bulletin, vol. 39, no. 1, pp. 15-24, 2006.

[50] M. Langemark and J. Olesen, "Sulpiride and paroxetine in the treatment of chronic tension-type headache. An explanatory double-blind trial," Headache, vol. 34, no. 1, pp. 20-24, 1994.

[51] C. A. Foster and J. Bafaloukos, "Paroxetine in the treatment of chronic daily headache," Headache, vol. 34 , no. 10, pp. 587-589, 1994. 
[52] A. A. Patkar, P. S. Masand, S. Krulewicz et al., "A randomized, controlled, trial of controlled release paroxetine in fibromyalgia," The American Journal of Medicine, vol. 120, no. 5, pp. 448454, 2007.

[53] S. H. Sindrup, L. F. Gram, K. Brøsen, O. Eshøj, and E. F. Mogensen, "The selective serotonin reuptake inhibitor paroxetine is effective in the treatment of diabetic neuropathy symptoms," Pain, vol. 42, no. 2, pp. 135-144, 1990.

[54] K. A. Holroyd, J. S. Labus, F. J. O’Donnell, and G. E. Cordingley, "Treating chronic tension-type headache not responding to amitriptyline hydrochloride with paroxetine hydrochloride: a pilot evaluation," Headache, vol. 43, no. 9, pp. 999-1004, 2003.

[55] J. Kwasucki, A. Stepien, G. Maksymiuk, and B. OlbrychKarpinska, "Evaluation of analgesic action of fluvoxamine compared with efficacy of imipramine and tramadol for treatment of sciatica-open trial," Wiad Lek, vol. 55, pp. 42-50, 2002.

[56] V. Manna, F. Bolino, and L. Di Cicco, "Chronic tension-type headache, mood depression and serotonin: therapeutic effects of fluvoxamine and mianserine," Headache, vol. 34, no. 1, pp. 44-49, 1994.

[57] D. Turkington, J. B. F. Grant, I. N. Ferrier, N. S. K. Rao, K. R. Linsley, and A. H. Young, "A randomized controlled trial of fluvoxamine in prostatodynia, a male somatoform pain disorder," Journal of Clinical Psychiatry, vol. 63, no. 9, pp. 778-781, 2002.

[58] M. Shimodozono, K. Kawahira, T. Kamishita, A. Ogata, S.-I. Tohgo, and N. Tanaka, "Reduction of central poststroke pain with the selective serotonin reuptake inhibitor fluvoxamine," International Journal of Neuroscience, vol. 112, no. 10, pp. 11731181, 2002.

[59] N. Moore, H. Verdoux, and B. Fantino, "Prospective, multicentre, randomized, double-blind study of the efficacy of escitalopram versus citalopram in outpatient treatment of major depressive disorder," International Clinical Psychopharmacology, vol. 20, no. 3, pp. 131-137, 2005.

[60] C. Sánchez, "The pharmacology of citalopram enantiomers: the antagonism by R-citalopram on the effect of S-citalopram," Basic and Clinical Pharmacology and Toxicology, vol. 99, no. 2, pp. 91-95, 2006.

[61] M. Mazza, O. Mazza, C. Pazzaglia, L. Padua, and S. Mazza, "Escitalopram $20 \mathrm{mg}$ versus duloxetine $60 \mathrm{mg}$ for the treatment of chronic low back pain," Expert Opinion on Pharmacotherapy, vol. 11, no. 7, pp. 1049-1052, 2010.

[62] J. E. Muller, I. Wentzel, L. Koen, D. J. H. Niehaus, S. Seedat, and D. J. Stein, "Escitalopram in the treatment of multisomatoform disorder: a double-blind, placebo-controlled trial," International Clinical Psychopharmacology, vol. 23, no. 1, pp. 43-48, 2008.

[63] M. Otto, F. W. Bach, T. S. Jensen, K. Brøsen, and S. H. Sindrup, "Escitalopram in painful polyneuropathy: a randomized, placebo-controlled, cross-over trial," Pain, vol. 139, no. 2, pp. 275-283, 2008.

[64] C. Villemure, B. M. Slotnick, and M. C. Bushnell, "Effects of odors on pain perception: deciphering the roles of emotion and attention," Pain, vol. 106, no. 1-2, pp. 101-108, 2003.

[65] R. Kenntner-Mabiala and P. Pauli, "Affective modulation of brain potentials to painful and nonpainful stimuli," Psychophysiology, vol. 42, no. 5, pp. 559-567, 2005.

[66] M. Roy, M. Piché, J.-I. Chen, I. Peretz, and P. Rainville, "Cerebral and spinal modulation of pain by emotions," Proceedings of the National Academy of Sciences of the United States of America, vol. 106, no. 49, pp. 20900-20905, 2009.
[67] M. W. Meagher, R. C. Arnau, and J. L. Rhudy, "Pain and emotion: effects of affective picture modulation," Psychosomatic Medicine, vol. 63, no. 1, pp. 79-90, 2001.

[68] M. K. Boettger, C. Schwier, and K.-J. Bär, "Sad mood increases pain sensitivity upon thermal grill illusion stimulation: implications for central pain processing," Pain, vol. 152, no. 1, pp. 123130, 2011.

[69] E. Horjales-Araujo, N. B. Finnerup, T. S. Jensen, and P. Svensson, "Differential effect of visual and gustatory stimuli on experimental jaw muscle pain," European Journal of Pain, vol. 17, no. 6, pp. 811-819, 2013. 


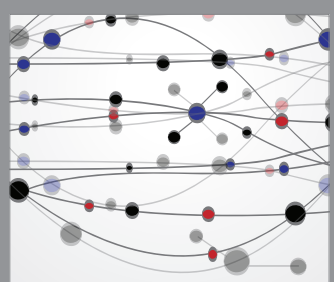

The Scientific World Journal
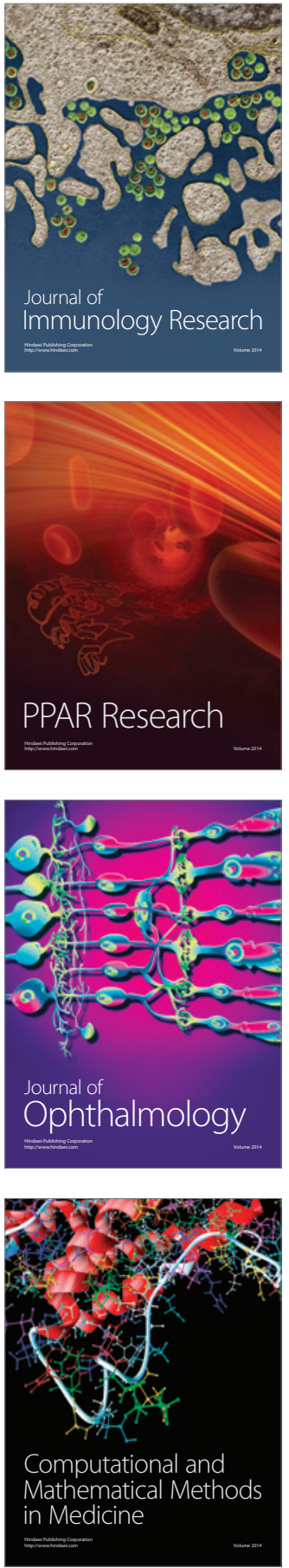

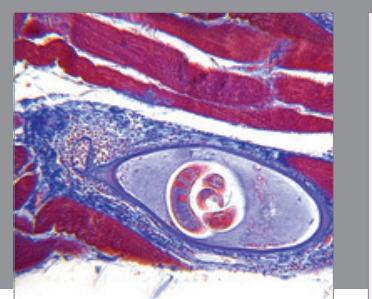

Gastroenterology Research and Practice

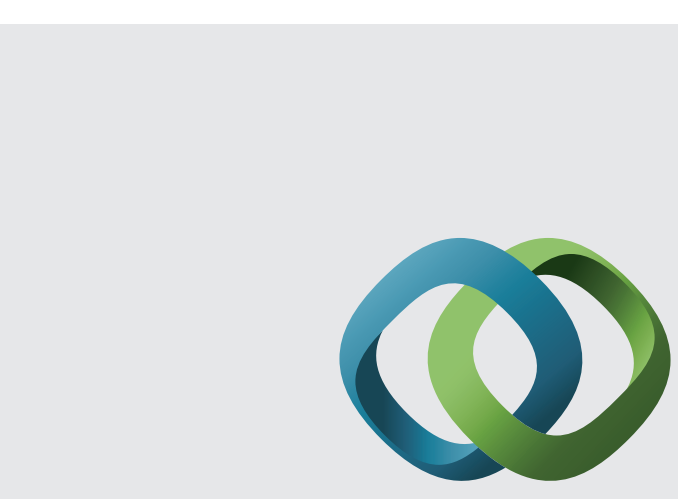

\section{Hindawi}

Submit your manuscripts at

http://www.hindawi.com
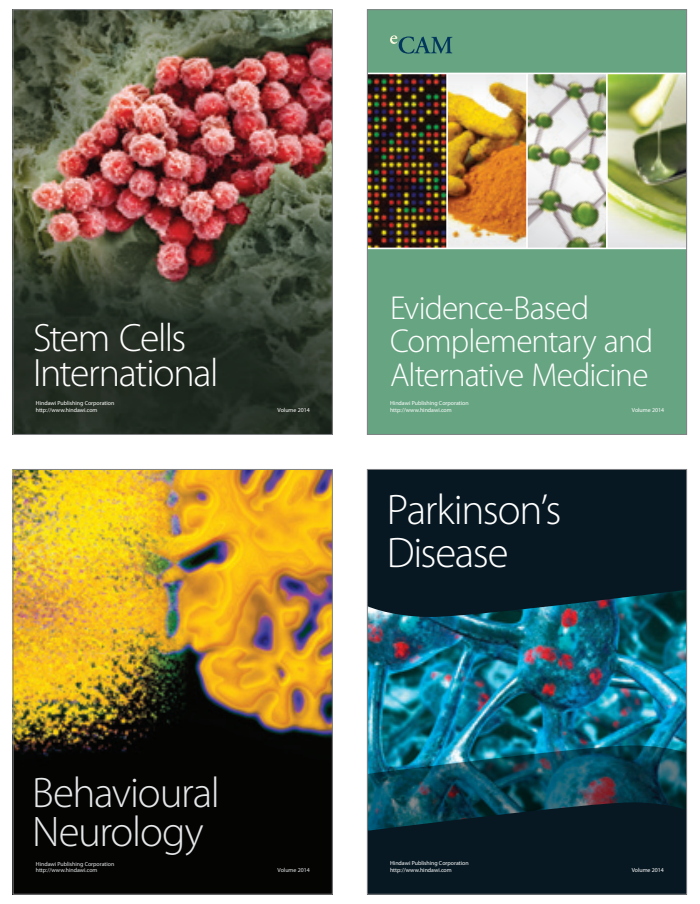
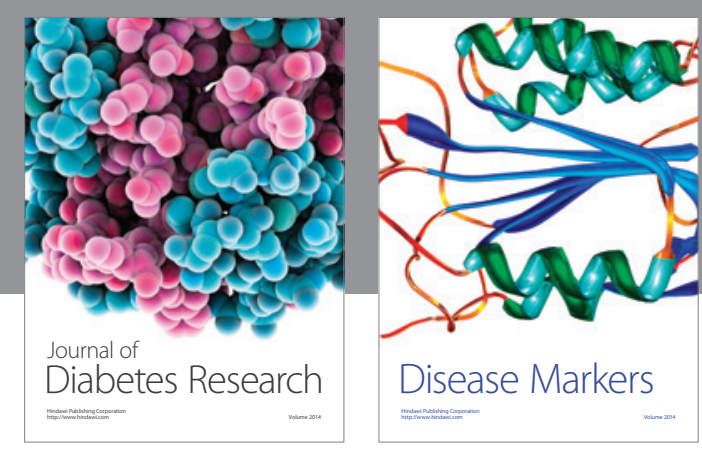

Disease Markers
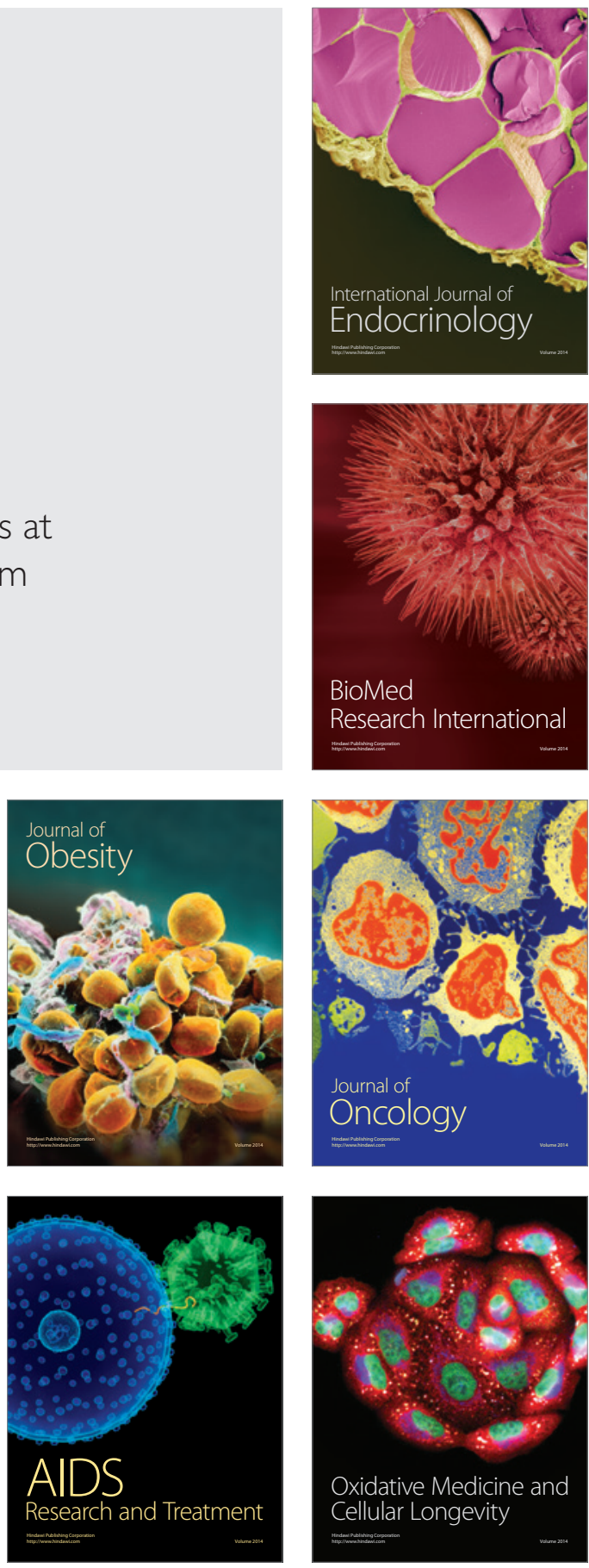